\title{
Enhanced Electron Transfer Reaction of Myoglobin in PEO by DNA/Bisbenzimide Complex
}

\author{
Hiroyuki $\mathrm{OHNO}^{\dagger}$ and Yoshikazu NAKAI \\ Department of Biotechnology, Tokyo University of Agriculture \& Technology, \\ Koganei, Tokyo 184-8588, Japan
}

(Received February 8, 1999)

\begin{abstract}
Double-stranded DNA was used as a molecular wire to enhance the electron transfer reaction between PEOmodified myoglobin (PEO-Mb) and electrode in PEO oligomers. No acceleration but suppression of electron transfer was found when only DNA was used. The $\pi$ stacking of base-pairs in DNA was enhanced by the complexation with bisbenzimide. Larger current of PEO-Mb was found under suitable values of the molar ratio of bisbenzimide to DNA base pair, the quantity of cast PEO-Mb, and the ratio of DNA base pair to PEO-Mb. DNA/bisbenzimide complex was revealed to be effective for the electron transfer reaction between heme-proteins and electrode even in ion conductive polymer matrix.
\end{abstract}

KEY WORDS DNA / Complexation / Electron Transfer / Myoglobin / Bisbenzimide / PEO

Poly(ethylene oxide) (PEO) is a very flexible polymer, and the dissociated ions can migrate in PEO by segmental motion. $\mathrm{PEO}$ has been focused on as solid polymer electrolytes because it shows excellent ionic conductivity even at room temperature. PEO can be regarded to be a polymerized water because of structural similarity. Quite a lot of materials are actually soluble in the PEO. We have been studying the electrochemistry of many target molecules such as not only inorganic salts but also organic molecules and even proteins. It has already been confirmed that hemeproteins, such as PEO-modified hemoglobin, myoglobin, and cytochrome $c$, dissolve and show redox activity in PEO oligomers. ${ }^{1-10}$ Moreover, these proteins are electrochemically redox active even at temperature higher than $100^{\circ} \mathrm{C}$ in PEO oligomers. ${ }^{4}$ The conformational change of proteins by heating is relatively little in PEO. Even after the addition of urea and guanidine hydrochloride which act as a denaturing agent in an aqueous phase, these proteins were stable and showed better electron transfer reaction in PEO. ${ }^{11}$ However, the electron transfer reaction of heme-proteins is slow in PEO oligomers, and fast electron transfer reaction was not observed even in the cast system because the electron transfer between proteins is slow.

On the other hand, it was recently reported that double helical DNA showed the electroconductivity and could act as an electroconductive molecular wire. ${ }^{12-16}$ Negative results were also reported, and active discussion has been continued. ${ }^{17}$ DNA is expected as a suitable material to construct aggregate at nano scale, in addition to the biological significance. Furthermore, DNA is also recognized to provide an oriented field of molecules to supply a supermolecular structure, because of following characteristic properties i) stable and ordered double stranded structure, ii) highly ordered $\pi$ stacked bases, iii) aligned anionic charges around rigid rod-like structure, and so on. Recently, Braun et al. reported the construction of a silver wire by the aggregation of the metallic silver on a double stranded DNA skeleton. $^{18}$ Takenaka et al. reported that a ferrocene-modified intercalator, bound to double stranded DNA by a threading intercalation mode, mediated the electron transfer reaction between glucose oxidase and a

\footnotetext{
${ }^{\dagger}$ To whom correspondence should be addressed.
}

DNA-immobilized electrode. ${ }^{19}$ It was reported by Barton et al. that methylene blue that bound to DNA on gold surfaces via intercalation showed good redox response, and the electron transfer was strongly suggested to occur through double stranded DNA. ${ }^{20}$

We have been studying the electroconductivity of DNA itself and tried to enhance the electron transfer reaction between PEO-Mb and the electrode in PEO oligomers by using DNA as a molecular wire. In the previous report, ${ }^{21}$ double stranded short-chain DNA with amino group on the 5 ' end, $\mathrm{NH}_{2} \cdot \mathrm{d}(\mathrm{CATGAAGTAC}) \cdot($ GTACTTCATG), was covalently bound to hemin, and was incorporated into the heme pocket of apo-myoglobin. Then this was further modified with activated PEO. Thus prepared PEO$\mathrm{Mb}(\mathrm{DNA})$ was soluble and electrochemically redox active in PEO oligomers. The charge of PEO-Mb(DNA) was found to be about two times larger than that of PEO-Mb in PEO oligomers. The possibility of the enhanced electron transfer by short chain DNA (10 base pairs) was suggested.

In this study, the increase of the peak current or charge of myoglobin in PEO was tried by using "long chain DNA" in DNA - PEO-Mb simply mixed system.

\section{EXPERIMENTAL}

\section{Materials}

PEO oligomers with average molecular weight of 400 $\left(\mathrm{PEO}_{400}\right)$, which were used as a polymer solvent, were purchased from NOF Co. Ltd. $\mathrm{PEO}_{400}$ was dried in vacuo at $60^{\circ} \mathrm{C}$ for a few days before use. Calf thymus DNA (CTDNA; $M_{w}=1.8 \times 10^{6}, M_{n}=8 \times 10^{5}$ ) was purchased from Fluka Co. Ltd. Horse skeletal muscle myoglobin (Mb) was purchased from Sigma Co. Ltd.

PEO-modified myoglobin (PEO-Mb) was prepared

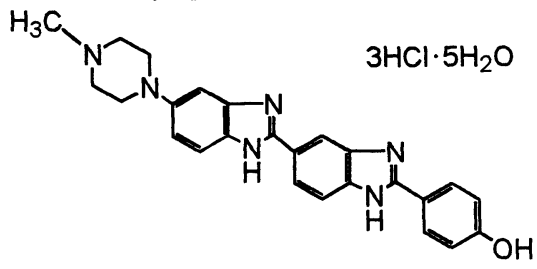

bisbenzimide 


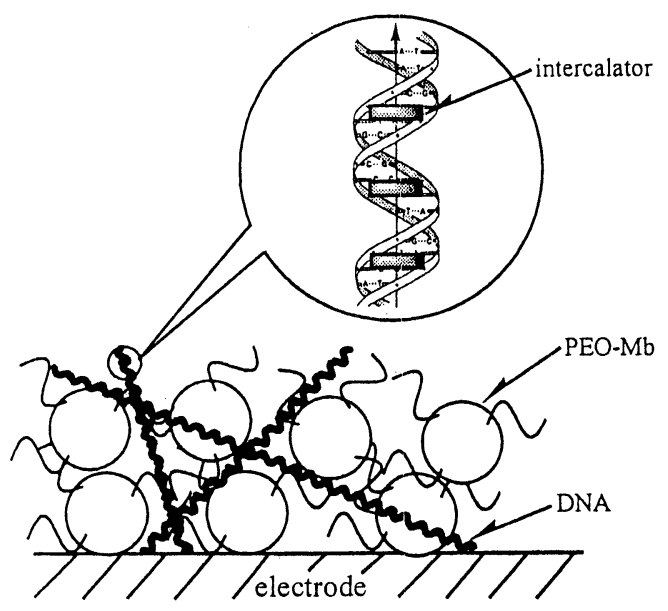

Scheme 1 Schematic illustration of PEO-Mb and DNA/intercalator complex cast on the electrode.

according to the method as reported previously. ${ }^{5}$ In the present study, myoglobin having 17 PEO chains with average molecular weight of 2000 was used.

The indium tin oxide (ITO) glass electrode (ITO layer thickness $=130 \mathrm{~nm}$, surface resistance $=30.9 \Omega \mathrm{cm}^{-2}$ ) was purchased from Oji Tobi Co. and was used after ultrasonic washing in ethanol, $1 \mathrm{M} \mathrm{NaOH}$ aq. and distilled water.

Bisbenzimide (Wako Co.Ltd.) was used for complexation with DNA. Bisbenzimide (BI) has been studied very well, and was also used for the development of electrochemical sensors $^{21}$ such as DNA chip. BI is a groove binder, which specifically binds to A-T base pairs. ${ }^{23-26}$

\section{Methods}

DNA was initially ultrasonicated at $60 \mathrm{~W}$ for $30 \mathrm{~min}$. by bath-type mild sonicator to reduce the molecular weight. Reduced molecular weight was not analyzed precisely, but the molecular weight distribution seemed to be considerably large. DNA aqueous solution $(300 \mathrm{mg} / \mathrm{l})$ was then mixed with BI aqueous solution $\left(1.25 \times 10^{-3} \mathrm{~mol} / \mathrm{l}\right)$. The complexation was evaluated from the increase of fluorescence intensity attributed to the BI. Fluorescence intensity of $\mathrm{BI}$ (its maximum emission wavelength $\left(\lambda_{\mathrm{em}}\right)$ was around $480 \mathrm{~nm}$ ) remarkably increased after complexation with DNA. DNA/BI complexes, formed in water, were confirmed to be stable in PEO oligomers from fluorescence intensity evaluation.

CT-DNA/BI complex and PEO-Mb (17 PEO chains of average molecular weight of 2000 were bound onto one myoglobin) were mixed and dissolved in $10 \mathrm{mM}$ Tris- $\mathrm{HCl}$ buffer ( $\mathrm{pH}$ 7.0). The ratio of BI to DNA base pair was changed from 0.02 to 0.20 . This solution was cast on the ITO glass working electrode and dried in vacuo for 1 hour. The thin-layer cell was prepared with this ITO glass electrode together with fresh ITO glass and Ag wire as a counter and a reference electrode, respectively. The CV measurement was performed in $\mathrm{PEO}_{400}$ containing $0.2 \mathrm{M} \mathrm{KCl}$. All $\mathrm{CV}$ measurements were carried out under nitrogen gas atmosphere.

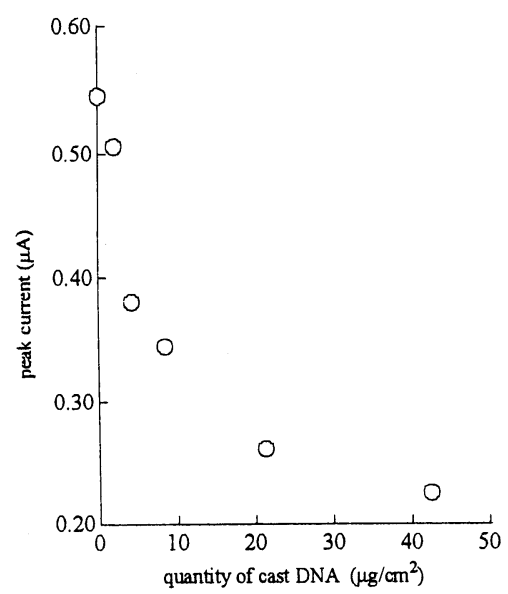

Figure 1 Effect of quantity of cast DNA on the peak current for PEO-Mb in $\mathrm{PEO}_{400}$ containing $0.2 \mathrm{M} \mathrm{KCl}$. $\left[\mathrm{PEO}_{2000}-\mathrm{Mb}\right]=2.13 \times 10^{-9} \mathrm{~mol} / \mathrm{cm}^{2}$.

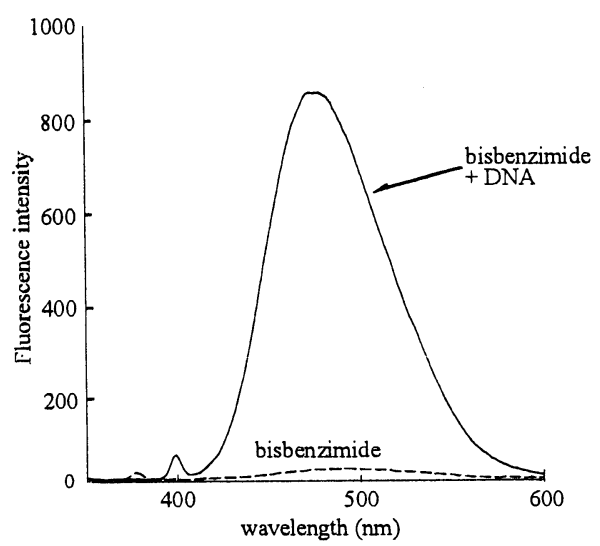

Figure 2 Fluorescence intensity of bisbenzimide $\left(\lambda_{\mathrm{ex}}=376.0 \mathrm{~nm}, \lambda_{\mathrm{em}}=\right.$ $489.6 \mathrm{~nm})$ and DNA/bisbenzimide complex $\left(\lambda_{\mathrm{ex}}=397.6 \mathrm{~nm}, \lambda_{\mathrm{em}}=476.8\right.$ $\mathrm{nm})$.

\section{RESULTS AND DISCUSSION}

The effect of DNA itself on the electron transfer of PEO$\mathrm{Mb}$ was analyzed. PEO-Mb, of which cast quantity was fixed to $2.13 \times 10^{-9} \mathrm{~mol} / \mathrm{cm}^{2}$, was mixed with DNA, and the $\mathrm{CV}$ measurement was carried out. The peak current decreased with increasing the quantity of DNA as seen in Figure 1. This result shows that the direct electron transfer of PEO-Mb was suppressed by the DNA chains on the electrode. At this stage, we reached one of conclusion that long chain DNA itself did not have electroconductivity, and the electron transfer reaction of PEO-Mb could not be enhanced by DNA itself.

However, double stranded DNA with only short chain length ( 10 base pair) seems to have the conductivity in our previous report. $^{21}$ It should be possible to make a longrange electron transfer when reduced conductive characteristics was enhanced by complexation. So, we tried to increase base-pair $\pi$ stacking of DNA by complexation to enable long-range DNA-mediated electron transfer (Scheme 1). A series of experiments were carried out in PEO oligomers. The intercalators were evaluated to form stable complex with DNA in PEO. From this point of view, lower solubility of the intercalator is better for the stable 


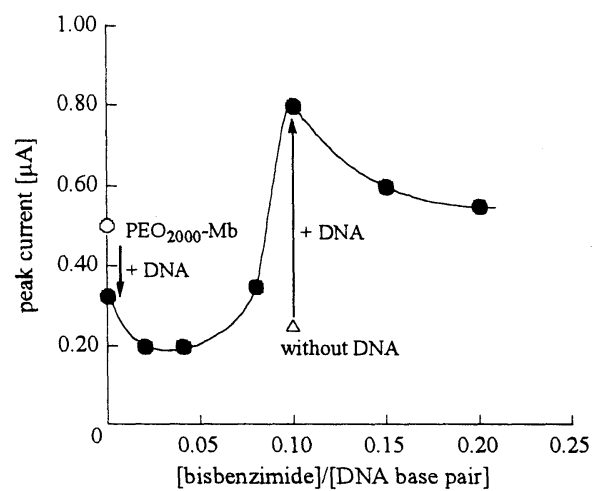

Figure 3 Effect of DNA/bisbenzimide complex on the anodic peak current for PEO-Mb cast on the ITO electrode in $\mathrm{PEO}_{400}$ containing $0.2 \mathrm{M}$ $\mathrm{KCl}$.

complexation. By fluorescence analysis, it was revealed that the solubility of BI was very low in PEO. Stable DNA/BI complex was formed by mixing DNA and BI in 10 $\mathrm{mM}$ Tris buffer ( $\mathrm{pH} 7.0)$. The complexation was confirmed by the increase of fluorescence intensity based on BI as shown in Figure 2.

The quantity of cast PEO-Mb and the molar ratio of DNA base pair to $\mathrm{PEO}-\mathrm{Mb}$ were fixed, and the molar ratio of intercalator to DNA base pair was varied from 0.02 to 0.20 . The peak current of PEO-Mb increased remarkably when the molar ratio of $[\mathrm{BI}] /[\mathrm{DNA}$ base pair] was 0.10 as shown in Figure 3. Its peak current was about 1.6 times larger and charge was about 1.5 times larger than those for PEO-Mb. The peak current of PEO-Mb decreased to $0.25 \mu \mathrm{A}$ when $\mathrm{PEO}-\mathrm{Mb}$ was mixed with $\mathrm{BI}$ (without DNA).

Instead of double stranded DNA, poly(sodium $p$-styrene sulfonate) (PSS, $M_{w}=70000$ ) was used. The ratio of BI to $-\mathrm{SO}_{3}^{-}$group was fixed to 0.10 to form the PSS/BI complex. This complex was then mixed with PEO-Mb, and these were coated on the ITO electrode. Modified electrode was dried sufficiently and CV measurement was performed in $\mathrm{PEO}_{400}$. However, the peak current of PEO-Mb was not increased and smaller peak current $(0.20 \mu \mathrm{A})$ was observed than PEO$\mathrm{Mb} / \mathrm{BI}$ simple mixture without DNA. This result shows that BI itself is impossible to act as a mediator. Only complexed-DNA enhanced the electron transfer reaction of PEO-Mb. The redox potential, observed in DNA/BI complex-PEO-Mb simply mixed system, was quite similar to that for PEO-Mb. Long chain DNA itself, cast on the electrode, was electrochemically redox inactive, and its peak current was not observed in PEO oligomers. The peak current derived from BI was not observed when BI or DNA/BI complex was cast on the electrode, supporting that the increased peak current was obviously derived from PEO$\mathrm{Mb}$. Furthermore, the peak separation decreased from 70 $\mathrm{mV}$ to $40 \mathrm{mV}$, suggesting the accelerated electron transfer reaction through DNA/BI complex. However, the peak current decreased when the ratio of BI to DNA base pair was increased more than 0.10 . This could not be fully explained at the present stage.

Figures 4 and 5 show sweep rate dependence of peak current and charge for PEO-Mb in the presence of DNA/BI

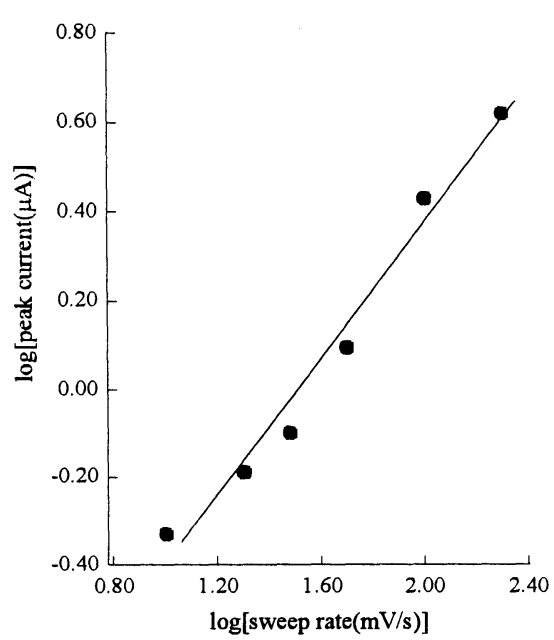

Figure 4 Sweep rate dependence of anodic peak current for PEO-Mb cast on the ITO electrode in $\mathrm{PEO}_{400}$ containing $0.2 \mathrm{M} \mathrm{KCl}$ (DNA : 4.25 $\mu \mathrm{g} / \mathrm{cm}^{2}\left(7.1 \times 10^{-9} \mathrm{~mol}\right.$ b.p. $\left./ \mathrm{cm}^{2}\right), \mathrm{PEO}_{2000}-\mathrm{Mb}: 2.13 \times 10^{-9} \mathrm{~mol} / \mathrm{cm}^{2}$, bisbenzimide : DNA base pair $=1: 10$ ).

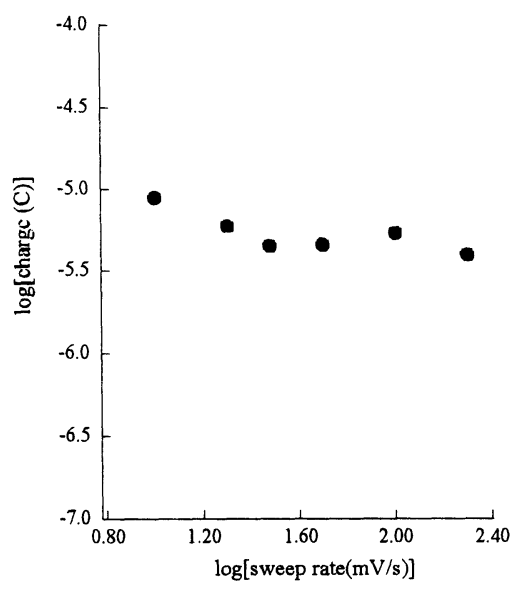

Figure 5 Sweep rate dependence of charge for PEO-Mb cast on the ITO electrode in $\mathrm{PEO}_{400}$ containing $0.2 \mathrm{M} \mathrm{KCl}\left(\mathrm{DNA}: 4.25 \mu \mathrm{g} / \mathrm{cm}^{2}\left(7.1 \times 10^{-9}\right.\right.$ mol b.p. $\left./ \mathrm{cm}^{2}\right), \mathrm{PEO}_{2000}-\mathrm{Mb}: 2.13 \times 10^{-9} \mathrm{~mol} / \mathrm{cm}^{2}$, bisbenzimide : DNA base pair $=1: 10$ ).

complex, respectively. The logarithm peak current was proportional to the logarithm sweep rate with the slope of about 1.0. And the charge was constant regardless of sweep rate. These results strongly suggest that $\mathrm{PEO}-\mathrm{Mb}$ and DNA/intercalator complex were tightly immobilized on the electrode and the redox response of these PEO-Mb was detected.

The increase of peak current was observed when the ratio of BI to DNA base pair was 0.10 . This tendency was also observed when other intercalators such as proflavine or aminacrine. ${ }^{27,28}$ Therefore, the electron transfer reaction of PEO-Mb was enhanced through complexed-DNA, when the ratio of intercalator to DNA base pair was set to be a suitable value.

Furthermore, the molar ratio of PEO-Mb/DNA base pair/ $\mathrm{BI}$ was fixed to $3 / 10 / 1$, and the cast quantity dependence of the peak current of PEO-Mb was investigated. The highest 
peak current was obtained, when the quantity of cast PEO$\mathrm{Mb}$ was $2.13 \times 10^{-9} \mathrm{~mol} / \mathrm{cm}^{2}$. The increase of base-pair $\pi$ stacking by complexation induced electron transfer through DNA, and it was strongly suggested that the electron transfer of PEO-Mb was certainly enhanced by DNA.

Therefore, DNA/BI complex was revealed to be effective for the increase of peak current or charge of myoglobin in PEO oligomers. The orientation of these DNA/intercalator complexes can be controlled on the electrode to enable more effective electron transfer.

Up to date, many studies about long-range DNA-mediated electron transfer have been reported, and the possibility as a molecular wire is suggested. All these electron transfer reactions were observed only in water. As mentioned above, the development of DNA into a "solid polymer system" could remarkably expand the possibility of DNA. It is without saying that the effect of molecular weight of solvent $\mathrm{PEO}$ on the electron transfer process should also be an important subject.

\section{CONCLUSION}

In order to enhance the electron transfer reaction of myoglobin in PEO, DNA/BI complex was cast with PEO-Mb on the ITO electrode. The peak current of PEO-Mb was increased about 1.6 times compared with $\mathrm{PEO}-\mathrm{Mb}$, when the quantity of cast PEO-Mb was $2.13 \times 10^{-9} \mathrm{~mol} / \mathrm{cm}^{2}$, the ratio of DNA base pair/PEO-Mb was a specific value, and the ratio of BI/DNA base pair was 0.10 . The electron transfer reaction of PEO-Mb was not enhanced by only long chain DNA or free BI. Even no positive effect was found when PSS/BI complex was used instead of DNA/BI complex.

Acknowledgment. This work was supported by the Grantin-Aid for Scientific Research on Priority Areas, "New Polymers and their Nano-Organized Systems" (No.277/08246101), from the Ministry of Education, Science, Sports and Culture, Japan.

\section{REFFERENCES}

1. H. Ohno, Electrochim. Acta, 37, 1649 (1992)

2. H. Ohno, J. Macromol. Sci., Pure \& Appl. Chem, A31, 83 (1994)

3. H. Ohno and N. Yamaguchi, Bioconjugate Chem., 5, 379 (1994)

4. N. Y. Kawahara and H. Ohno, Bioconjugate Chem., 8, 643 (1997)

5. H. Ohno and T. Tsukuda, J.Electroanal. Cham., 341, 137 (1992)

6. H. Ohno and T. Tsukuda, J. Electroanal. Cham., 367, 189 (1994)

7. N. Y. Kawahara, W. Ohkubo and H. Ohno, Bioconjugate Chem., 8, 244 (1997)

8. F. Kurusu, N. Y. Kawahara and H. Ohno, Solid State Ionics, 86-88, 337 (1996)

9. H. Ohno and F. Kurusu, Chem.Lett., 693 (1996)

10. B. N. Oliver, J. O. Egekeze, and R. W. Murray, J. Am. Chem. Soc., 110, 2321 (1988)

11. N. Y. Kawahara and H. Ohno, Extended Abstracts of the $6^{\text {th }}$ International Symposium on Polymer Electrolytes, 82 (1998)

12. P. Fromhertz and B. Rieger, J. Am. Chem. Soc., 108, 5361 (1986)

13. A. M. Brum and A. Harriman, J. Am. Chem. Soc., 114, 3656 (1992)

14. C. J. Murphy, M. R. Arkin, Y. Jenkins, N. D. Ghatlia, S.H. Bossmann, N. J. Turro, and J. K. Barton, Science, 262, 1025 (1993)

15. T. J. Meade and J. F. Kayyem, Angew. Chem. Int. Ed. Engl., 34, 352 (1995)

16. F. D. Lewis, T. Wu, Y. Zhang, R. L. Letsinger, S. R. Greenfield, and M. R. Wasielewski, Science, 277, 673 (1997)

17. T. Taube, Science, 275, 1420 (1997)

18. E. Braun, Y. Eichen, U. Sivan, and G. Ben-Yoseph, Nature, 391, 775 (1998)

19. S. Takenaka, Y. Uto, M. Takagi, and H. Kondo, Chem.Lett., 989 (1998)

20. S. O. Kelley and J. K. Barton, Bioconjugate Chem., 8, 31 (1997)

21. K. Muneyasu, N. Y. Kawahara, and H. Ohno, Solid State Ionics, 113-115, 167 (1998)

22. K. Hashimoto, K. Ito, and Y. Ishimori, Anal. Chem., 66, 3830 (1994)

23. C. Labarca and K. Paigen, Anal. Biochem., 102, 344 (1980)

24. T. R. Downs and W. W. Wilfinger, Anal. Biochem., 131, 538 (1983)

25. F. G. Loontiens, L. W. McLaughlin, and S. Diekmann, and R. M. Clegg, Biochemistry, 30, 182 (1991)

26. P. R. Turner and W. A. Denny, Mutation Research, 355, 129 (1996)

27. K. Miyata, Y. Nakai, and H. Ohno, the 76th Annual Meeting Proceedings of Chemical Society of Japan, 2H247 (1999)

28. Y. Nakai, K. Miyata, and H. Ohno, the 66th Annual Meeting Proceedings of Electrochemical Society of Japan, 1E21 (1999) 